\title{
Simulation of the Ozone Pretreatment of Wheat Straw
}

Sujala Bhattarai ${ }^{1}$, Danny Bottenus ${ }^{2}$, Cornelius F. Ivory ${ }^{2 *}$, Allan Haiming Gao ${ }^{1}$, Mahesh Bule ${ }^{1}$, Manuel Garcia-Perez ${ }^{1}$, Shulin Chen $^{1}$

${ }^{1}$ Department of Biological Systems Engineering, Washington State University, Pullman 991646120, United States

${ }^{2}$ Gene and Linda Voiland School of Chemical Engineering and Bioengineering, Washington State University, P.O. Box 646515, Pullman, WA, 99164-6515, United States

\section{*Corresponding author:}

Tel.: +1 509335 7716; fax: +1 5093354806

Email Address: cfivory@wsu.edu 
Keywords: wheat straw; ozone pretreatment; mathematical modeling; cuticle hypothesis 
Nomenclature

$C I_{i}$
$c_{i i}$
$C o v$
$D F$
$D_{O 3}$
$d_{p}$
$i L g$
$i L g_{C}$
$i L g_{C, 0}$
$i L_{C, \text { Model,i }}$

$i \operatorname{Lg}_{C, \text { Model }, i}$

$i L g_{E x p, i}$

$i g_{\text {Model }, i}$

$i L g_{S}$

$J$

$k_{1}$

$k_{2}$

$K_{O, C S} a_{p}$

$$
K_{O, G C} a_{p}
$$

$K_{O, S} a_{p}$

K

$\mathrm{O}_{3, \mathrm{C}}$

$O_{3, G}$

$O_{3, S}$

confidence intervals

$i^{\text {th }}$ diagonal element of covariance matrix

covariance matrix

degree of freedom

diffusion coefficient, $\mathrm{m}^{2} / \mathrm{s}$

diameter of particle, $\mathrm{m}$

insoluble lignin, $\mathrm{kg} \_\mathrm{ig} / \mathrm{kg}_{\text {Straw }}$

insoluble lignin in cuticle, $\mathrm{kg} i \mathrm{Lg} / \mathrm{kg}_{\text {Straw }}$

initial insoluble lignin in cuticle, $\mathrm{kg} \_i \mathrm{Lg} / \mathrm{kg}_{\text {Straw }}$

predicted insoluble cuticle lignin,

$\mathrm{kg} i \mathrm{Lg} / \mathrm{kg}_{\text {Straw }}$

experimental insoluble lignin, $\mathrm{kg} i \mathrm{Lg} / \mathrm{kg} g_{\text {Straw }}$

predicted insoluble lignin, $\mathrm{kg} \_i \mathrm{Lg} / \mathrm{kg}_{\text {Straw }}$

insoluble lignin of solid, $\mathrm{kg} \_i \mathrm{Lg} / \mathrm{kg}_{\text {Straw }}$

Jacobian matrix

reaction rate, $\mathrm{kg}_{\text {Straw }} / \mathrm{kg} i \mathrm{Lg} / \mathrm{min}$

reaction rate, $\mathrm{kg}_{\text {Straw }} / \mathrm{kg} \_\mathrm{s} L \mathrm{~g} / \mathrm{min}$

mass transfer coefficient between cuticle and the interior solid, $1 / \mathrm{min}$

mass transfer coefficient between gas phase and the cuticle, $1 / \mathrm{min}$

mass transfer coefficient between gas phase and solid phase, $1 / \mathrm{min}$

condition number

ozone in the cuticle, $\mathrm{kg}_{-} \mathrm{O}_{3,5} / \mathrm{kg}_{\text {Straw }}$

ozone in the gas phase, $\mathrm{kg}_{-} \mathrm{O}_{3, G} / \mathrm{kg}_{\text {Straw }}$

ozone in the solid phase, $\mathrm{kg}_{-} \mathrm{O}_{3,5} / \mathrm{kg}_{\text {Straw }}$ 
best fit parameter

$P$

pressure, pa

$P$

PI

$R_{1}$

$R_{2}$

$R_{1, C}$

$R_{2, C}$

products

prediction interval

reaction kinetics, $\mathrm{kg}_{\text {Straw }} \cdot \mathrm{kg} \_s \mathrm{Lg} / \mathrm{min}$

reaction kinetics, $\mathrm{kg}_{\text {Straw }} \cdot \mathrm{kg} \_s \mathrm{Lg} / \mathrm{min}$

reaction kinetics, $\mathrm{kg}_{\text {Straw }} \cdot \mathrm{kg} \_\mathrm{s} L \mathrm{~g} / \mathrm{min}$

reaction kinetics, $\mathrm{kg}_{\text {Straw }} \cdot \mathrm{kg} \_s \mathrm{Lg} / \mathrm{min}$

$R_{1, S}$

reaction kinetics, $\mathrm{kg}_{\text {Straw }} \cdot \mathrm{kg} \_s \mathrm{Lg} / \mathrm{min}$

$R_{2, S}$

reaction kinetics, $\mathrm{kg}_{\text {Straw }} \cdot \mathrm{kg} \_s L g /$ min

$S E$

standard error

$s L g$

$s L g_{C}$

$s L g_{c, \text { Model }, i}$

$s L g_{c, E x p, i}$

$s L g_{\text {Model }, i}$

$s L g_{S}$

$T$

$t_{\alpha / 2, D f}$

$U$

$V_{s}$

$W_{s}$

Z

Greek

$\alpha_{1}, \alpha_{4}$

$\alpha_{2}$

$\alpha_{3}$

stoichiometric, dimensionless

stoichiometric, $\mathrm{kg} \_\mathrm{iLg} / \mathrm{kg} \_\mathrm{O}_{3, S}$

stoichiometric, $k g \_s L g / k g \_O_{3, S}$ 


$\begin{array}{ll}\alpha_{5} & \text { stoichiometric, } \mathrm{kg} \_\mathrm{S} L \mathrm{~kg} \_\mathrm{O}_{3, S} \\ \epsilon & \text { void fraction, dimensionless } \\ \rho_{S}, \rho & \text { density of solid, } \mathrm{kg} / \mathrm{m}^{3} \\ \lambda_{c} & \text { cuticle lignin fraction, dimensionless } \\ \mu & \text { dynamic viscosity, pa sec } \\ \kappa_{b r} & \text { permeability, } \mathrm{m}^{2} \\ \lambda_{\max } & \text { largest eigen value } \\ \lambda_{\min } & \text { smallest eigen value } \\ \beta_{F} & \text { Forchheimer drag coefficient, } \mathrm{kg} / \mathrm{m}^{4} \\ \Phi & \text { sphericity, dimensionless } \\ \Theta_{i} & \text { best fit parameter } \\ \Delta & \text { square root of machine precision } \\ A & \text { confidence interval }\end{array}$




\section{Introduction}

Wheat straw is an agricultural byproduct of wheat that is annually produced in abundance around the world. The world's wheat production in 2014 was 716 Tg (USDA (2014). Assuming a residue/crop ratio of 1.3 (Talebnia et al., 2010), about $931 \mathrm{Tg}$ of total wheat residue is annually produced. If $60 \%$ is used for ground cover to prevent soil erosion $559 \mathrm{Tg}$ of wheat straw is available as waste. Wheat straw is composed of lignin (15-20\%), celluloses (33-40\%), and hemicelluloses (20-25\%) (Talebnia et al., 2010). The lignin in the wheat straw is made up of monomer units such as p-hydroxyphenyl-guaiacyl-syringyl (H-G-S) lignin, and contains approximately 5, 49, and 46\% of H, G, and S units, respectively (Lapierre et al., 1995). In order to utilize structural carbohydrates of the wheat straw in a biochemical biorefinery setting, a pretreatment process is necessary to disrupt the recalcitrant structure of mainly lignin.

Pretreatment is known to increase the susceptibility of cellulose and hemicellulose to celluloytic enzymes for the production of fermentable sugars. The main goal of pretreatment process is to increase the surface area and porosity of the substrate, reduce the crystallinity of the cellulose, degrade hemicellulose and lignin, and disrupt the heterogeneous structure of the cellulosic materials (Talebnia et al., 2010). The pretreatment processes are of four types: physical, physicochemical, chemical, and biological. Physical pretreatment is based on size reduction of the wheat straw by means of milling, grinding, or chipping (Pedersen and Meyer, 2009). Liquid hot water (Petersen et al., 2009), steam explosion (Ballesteros et al., 2006), and ammonia fiber explosion (Sun and Cheng, 2002) are the physico-chemical pretreatment methods. The use of acids, alkalines, and oxidizing agents for the pretreatment of wheat straw is known as chemical pretreatment (Saha et al., 2005). The pretreatment by means of microorganisms such as white and soft rot fungi are types of biological pretreatment (Talebnia et al., 2010). 
Ozone pretreatment uses ozone as an oxidizing agent. Ozone is a very powerful oxidizing species with an oxidation potential of $2.07 \mathrm{eV}$ (Mandavgane and Yenkie, 2011). There are many advantages of the ozone pretreatment process compared to other pretreatment techniques. For instance, ozone causes minimal degradation of cellulose and hemicelluloses due to the considerably higher reaction rate of ozone with substituted aromatic molecules such as lignin. The ozonation process also does not produce toxic compounds and can be performed at room temperature and pressure, which reduces the capital and energy costs ( Neely, 1984). In addition, earlier studies demonstrated efficiency of ozone pretreatment to improve sugar release during enzymatic hydrolysis (Bule et al., 2013; García-Cubero et al., 2009; Wu et al., 2013).

The majority of studies involving the ozonation pretreatment of lignocellulose required a relatively long residence time in the reactor, typically 60 minutes or greater. As a result, utilizing ozone as a sole pretreatment process for lignocellulose can be unpractical. The study demonstrating ozonolysis of wheat straw and rye straw which increased sugar yield from $29 \%$ and $16 \%$ (untreated) to $88.6 \%$ and $57 \%$ (ozone treated), respectively (untreated) (García-Cubero et al., 2009) required $2.5 \mathrm{~h}$ of ozone exposure. Also, the ozonolysis of sugarcane bagasse showed an increase in glucose yield from $6.64 \%$ (untreated) to $52.44 \%$ (ozone treated) after 120 minutes of ozone pretreatment (Travaini et al., 2013). In contrast, the ozonolysis (for 120 minutes) of energy grasses showed a lower sugar yield compared to untreated energy grasses after enzymatic hydrolysis (Panneerselvam et al., 2013). These observations suggest that the applicability of ozone pretreatment depends upon the biomass characteristics. In order to make ozone pretreatment economically feasible, its optimization either through better elucidation of the ozone interaction with lignin or through the reduction of the overall pretreatment time is urgently needed. 
Although many studies have been conducted on the ozonolysis process, mathematical models explicitly predicting ozone lignin degradation phenomena are rare. García-Cubero et al. (2012) introduced a model to characterize the effects of ozonation on the insoluble and soluble lignin (MBachu and Manley, 1981) content of biomass. However, the model presented by García-Cubero et al. (2012) did not take into account the residual lignin that remained unaffected by the ozone. In contrast, their model predicts that prolonged ozone exposure removes lignin completely, with contradicts experimental results where lignin concentration reaches a plateau.

Several attempts have been made in the development of numerical models for the ozone lignin interaction process. The kinetic model proposed by Binder et al. (1980) showed that the ozone lignin interaction has two different kinetic behaviors: a falling rate phase followed by a constant rate phase, however, only the falling rate period was addressed in their model. Mbachu andManley (1981) suggested that lignin degradation follows first-order kinetics, and they derived the first order reaction equation of lignin degradation of ozone treated spruce periodate and spruce cuoxam lignin as follows:

$$
\log _{10} \frac{L_{0}}{L}=\frac{K \cdot t}{2.303}
$$

where $L_{0}$ is the initial amount of lignin in grams, $L$ is the amount of undissolved lignin at time $t$, and $K$ is the rate constant. Their study showed that prolonged ozone exposure does not result in a change in the lignin content of wood. Therefore, they speculated that a small portion of the lignin was resistant to ozone degradation. Also another study found moisture content, particle size, reaction time, degree of ozone consumption, and lignocellulose origin were significant factors affecting the ozone lignin interaction process (Neely, 1984). The recommended range of moisture content for efficient ozonolysis ranged between 25-35\% (w.b.) (Bule et al., 2013; 
Neely, 1984). Mathematical modeling of ozonolysis process will be more helpful for developing pretreatment methodologies for different lignocellulosic biomasses.

The main goal of this study is to modify the García-Cubero et al. (2012) model and to present a simulation study on the ozone pretreatment of wheat straw explicitly. In the present work, two models were developed and studied: one similar to the Garcia-Cubero et al. (2012) model and another that employ a hypothesis that mathematically takes into account the residual lignin by effectively shutting off the mass transfer of the ozone to the lignin. Each model was fit using experimental results and the effectiveness of each model was compared and analyzed based on the prediction intervals. The reaction kinetics and mass transfer coefficients were estimated using each of the models. The precise expression between the simulation and the experiment supports the proposed formation of mass transfer barrier, named as "cuticle" hypothesis. Additionally, the flow behavior of the ozone inside the reactor was studied using a computational fluid dynamics (CFD) module in COMSOL v4.3b. CFD was performed to analyze the flow of ozone and the pressure drop inside the reactor, which makes it possible to construct the simple kinetic model for ozonolysis process.

\section{Materials and Methods}

\subsection{Wheat Straw Ozonation}

Wheat straw (Triticum aestivum) was obtained from the Grange Supply Co. in Pullman WA and hammer milled at the Washington State University's Wood Materials and Engineering Laboratory. The size of wheat straw particles ranged from $0.05 \sim 1 \mathrm{~mm}$. The wheat straw was composed of $58 \%$ cellulose and hemicellose and $21 \%$ lignin. Fig. 1 shows the experimental set up. The ozonation experiment was conducted in a fixed bed reactor. The reactor was $20 \mathrm{~cm}$ in 
height and $6.5 \mathrm{~cm}$ in diameter. $3 \mathrm{~g}$ of wheat straw was placed on the tray, which was $\sim 9 \mathrm{~cm}$ below the inlet. The tray was $1.5 \mathrm{~cm}$ in height and $6.5 \mathrm{~cm}$ in diameter. The thickness of the wheat straw bed in the tray was $1 \mathrm{~cm}$. The ozone inlet and outlet vents were $0.5 \mathrm{~cm}$ in diameter. A deflector was positioned directly underneath the oxygen inlet to check the velocity distribution and to maintain a uniform discharge of the ozone/oxygen mixture.

Fig. 1(b) shows a schematic of the ozonolysis process. The ozone generator (L11-L24 ozone generator from Pacific Ozone, Benicia, California) was used to produce ozone with 99.5\% oxygen as a feed gas. The ozone and oxygen mixture was then passed into the reactor to treat the wheat straw. Ozonation reactions were performed with $5.3 \%(\mathrm{w} / \mathrm{w})$ ozone concentration at an oxygen flow rate of $2 \mathrm{~L} / \mathrm{min}$ at different pretreatment times $(0,1,2,3,5,7,10,15,20,30,60$ min). Ozone concentration at $2 \mathrm{~L} / \mathrm{min}$ oxygen flow rate was calculated with the analytical produced explained in Rakness et al. (1996). Ozonolysis was performed at room temperature. The wheat straw particle size distribution was determined using ASTM standard sieves. A dry mass of wheat straw was placed on a series of sieves arranged in order of increasing fineness (1 $\mathrm{mm}$ to $0.05 \mathrm{~mm}$ ) and the mass was divided into fractions corresponding to the sieve opening. Considering the normal distribution of the materials, the mean particle size was calculated. Moisture content of the wheat straw was measured using oven-drying experiments (CEN/TC, 2004) as previously described. Ozonated wheat straw particles were dried to a constant weight in an oven at $105{ }^{\circ} \mathrm{C}$ for $24 \mathrm{~h}$.

2.2 Measurement of the bulk density of wheat straw.

The bulk density of the wheat straw was determined according to the ASAE standard S269.4 DEC 91(ASABE, 2007) for cubes, pellets, and crumbles. Wheat straw was filled into a cylindrical container that was $10 \mathrm{~cm}$ in diameter and $15 \mathrm{~cm}$ in height. Wheat straw in the 
containers was compacted by dropping it to $10 \mathrm{~cm}$ in height, measured from the bottom of the container. The weight of the wheat straw with the container was recorded. The net weight of the sample $\left(W_{s}\right)$ was obtained by subtracting the weight of the empty container from the weight of the filled container. Each experiment was repeated three times for $2 \%$ and $47 \%$ moisture content, respectively. The bulk density, $\rho_{S}$, of the bed of wheat straw was calculated by dividing the sample weight $\left(W_{s}\right)$ by the volume of container $\left(V_{s}\right)$ as follows (Lam et al., 2008):

$$
\rho_{S}=\frac{W_{s}}{V_{s}} .
$$

\subsection{Measurement of void fraction}

The void fraction, $\varepsilon$, of the packed wheat straw was determined in the laboratory by using a volume displacement method (Thompson and Isaacs, 1967). Two equal volumes of cylindrical containers were used. The first container was filled with water and the second was filled with wheat straw of a known moisture content. Then, the water from one container was continuously poured into wheat straw until the wheat straw became saturated. Next, the weight of remaining water in the first container was measured. The volume of voids $\left(V_{v}\right)$ was equal to the volume of water poured into the second container. The volume of water poured into the second container was the difference between the initial weight of water to the final weight of water. The volume of solids $\left(V_{s}\right)$ was equal to the initial volume of the container. The void ratio was calculated as follows:

$$
\varepsilon=\frac{V_{v}}{V_{s}} .
$$




\subsection{Measurement of pressure drop inside the reactor}

A $U$ tube manometer was connected to the reactor to observe the pressure drop along the bed (Dean, 1953). The pressure drop was measured for various flow rates of oxygen in the range of 0.5 to $3.5 \mathrm{~L} / \mathrm{min}$. The flow meter from the ozone generator was used to control the ozone flow rate.

\subsection{Measurement of lignin content}

Ozone pretreated and untreated wheat straw samples were dried in a hot air oven at 105

${ }^{\circ} \mathrm{C}$ for $24 \mathrm{~h}$ and then used to determine the lignin concentration. Drying was performed to reduce the moisture content to zero. Lignin contents were determined by following the National Renewable Energy Laboratory (NREL) standard laboratory analytical procedure (LAP) for the determination of the structural carbohydrates in biomass (Sluiter et al., 2006). Samples were hydrolyzed using a two-step process by first dissolving them in sulfuric acid ( $3 \mathrm{~mL}$ of $72 \%$ (w/w) for $3 \mathrm{~g}$ sample) at $40{ }^{\circ} \mathrm{C}$. After the initial hydrolysis, the samples were diluted with distilled water to a total volume of $84 \mathrm{~mL}$ and autoclaved for $1 \mathrm{~h}$ in pressure tubes.

\subsection{Software used}

COMSOL Multiphysics v.4.3b, Mathematica ${ }^{\circledR}$ NonlinearModelFit function, and Matlab software were used in this study. The flow of ozone in the reactor was studied using COMSOL Multiphysics v.4.3b, the nonlinear fit of the Ergun equation was conducted in Mathematica ${ }^{\circledR}$ NonlinearModelFit function, and statistical analysis was performed in Matlab.

\subsection{Enzymatic hydrolysis}

The enzymatic hydrolysis was performed on the untreated and ozonated wheat straw samples to study the sugar recovery with increasing ozonolysis time. The hydrolysis was 
conducted at $1 \mathrm{wt} . \%$ solid loading of unwashed ozonated samples in $50 \mathrm{mM}$ sodium citrate buffer (pH 4.8) with $30 \mathrm{FPU} / \mathrm{g}$ of cellulase (Novozymes NS 50013) and $30 \mathrm{CBU} / \mathrm{g}$ of $\beta$ glucosidase (Novozymes NS 50010) at $50{ }^{\circ} \mathrm{C}$ for $72 \mathrm{~h}$ in an orbital incubator shaker (Gyromax 747). The total released sugars after $72 \mathrm{~h}$ were used to calculate sugar recovery after enzymatic hydrolysis (Bule et al., 2013).

\section{Model Development}

The following assumptions were used for model development:

1. The wheat straw particles are loosely packed in a shallow bed and are assumed to be homogenous in size and shape.

2. The stationary bed of wheat straw is rapidly and uniformly exposed to the mobile ozone phase, and the mass transfer from the gas phase to the solid phase is rapid.

3. Ozone only reacts with soluble and insoluble lignin in the biomass particles.

4. Ozone-lignin reactions are considered to be bimolecular and irreversible.

Momentum Balance

A study of the flow properties of the fixed bed ozone reactor was performed in COMSOL Multiphysics v.4.3b using the free and porous media flow physics in the CFD module, which integrates the functionality of the laminar flow physics with the Brinkman equations physics. Flow in the entrance and exit tubes as well as in the open space above and below the packed bed is described by the Navier-Stokes equations such that:

$$
\begin{aligned}
& \rho \frac{D u}{D t}=\nabla \cdot\left[-p \mathbf{I}+\mu\left(\nabla u+(\nabla u)^{T}\right)\right] \\
& \nabla . \rho u=0
\end{aligned}
$$


where $\mu$ denotes the dynamic viscosity ( $\mathrm{Pa} \mathrm{s}, u$ is the vector velocity in the open reactor outside the packed bed $(\mathrm{m} / \mathrm{s}), \rho$ is the fluid density $\left(\mathrm{kg} / \mathrm{m}^{3}\right), p$ is the dynamic pressure $(\mathrm{Pa})$ and $\mathbf{I}$ is the unit tensor. In the packed bed region of the reactor, the Brinkman equations describe the flow such that:

$$
\begin{aligned}
& \frac{\rho}{\varepsilon} \frac{D u}{D t}=\nabla \cdot\left[-p \mathbf{I}+\frac{\mu}{\varepsilon}\left(\nabla u+(\nabla u)^{T}\right)\right]-\left(\frac{\mu}{\kappa_{b r}}+\beta_{F}|u|\right) u \\
& \nabla . \rho u=0
\end{aligned}
$$

where $u$ is the superficial velocity $(\mathrm{m} / \mathrm{s})$ in the packed bed, $\kappa_{b r}$ is the permeability of the bed $\left(\mathrm{m}^{2}\right), \varepsilon$ is the porosity or void fraction of the bed, and $\beta_{F}$ is the Forchheimer drag coefficient $\left(\mathrm{kg} / \mathrm{m}^{4}\right)$ (Whitaker, 1996).

The boundary conditions on the reactor surfaces are: no slip on the vessel surfaces, $u=u_{\text {inlet }}(0.6 \mathrm{~m} / \mathrm{min}$, calculated by dividing the flow rate of ozone, $2 \mathrm{~L} / \mathrm{min})$ with the crosssectional area of reactor) at the top of the reactor and no normal stresses act on the outlet flow at the bottom of the reactor.

The Reynolds number in the inlet and outlet section of the reactor was less than 700 , which implies that the inlet flow is laminar. After the flow passes the deflector, the Reynolds number drops to 60 in the empty body of the reactor and to 0.002 in the packed bed, indicating that the flow is laminar everywhere in the reactor vessel. The Darcy-Forchheimer equation (Whitaker, 1996) was used to determine the permeability and Forchheimer drag coefficient, and Kozeny-Carman (Carman, 1956) equation was used to calculate the sphericity of the particles.

$$
\varphi=\sqrt{\frac{180 \kappa_{b r}(1-\varepsilon)^{2}}{\varepsilon^{3} d_{p}{ }^{2}}}
$$

where $\varepsilon$ is the bed void fraction; $d_{p}$ is the sieve particle diameter $(\mathrm{m})$, and $\Phi$ is the empiricallydetermined particle sphericity. Sphericity is a measure of how spherical a particle is relative to 
actual spherical particles. The sphericity is equal to 1 when the particles are spherical; otherwise, it is less than 1.

Mass Balance

Following García-Cubero et al. (2012), the mass balance equations used to determine the amount of ozone in the solid phase and the concentrations of soluble and insoluble lignin are:

$$
\varepsilon \frac{\partial O_{3, G}}{\partial t}+u \frac{\partial O_{3, G}}{\partial z}=-K_{O, S} a_{p}\left(O_{3, G}-\frac{\rho_{S} O_{3, S}}{(1-\varepsilon)}\right)
$$

where $O_{3, G}$ is the ozone concentration in the gas phase, $O_{3, S}$ is the ozone concentration in the solid phase, $u$ is the superficial velocity in the porous phase, $K_{O, S}$ is an overall mass transfer coefficient between the gas and solid phases and $a_{p}$ is the interfacial area of the solid phase per unit volume of packed bed, $\varepsilon$ is the void fraction, and $\rho_{S}$ is the density of the packed wheat straw bed. The time evolution of the ozone in the solid phase is given by the equation:

$$
\frac{\partial O_{3, S}}{\partial t}=\frac{K_{O, S} a_{p}}{(1-\varepsilon)}\left(\frac{(1-\varepsilon)}{\rho_{S}} O_{3, G}-O_{3, S}\right)-\alpha_{1} R_{1}-\alpha_{4} R_{2}
$$

where $R_{1}$ and $R_{2}$ are elementary bimolecular reaction rates for ozone in the solid phase reacting with insoluble and soluble lignin, respectively. The equations for the time evolution of insoluble, $i L g$, and soluble, $s L g$, lignin are:

$$
\begin{aligned}
& \frac{\partial(i L g)}{\partial t}=-\alpha_{2} R_{1} \\
& \frac{\partial(s L g)}{\partial t}=\alpha_{3} R_{1}-\alpha_{5} R_{2}
\end{aligned}
$$

where it should be noted that a portion of the insoluble lignin is converted to soluble lignin via the $R_{l}$ reaction according to eq.[9b]. 
In the packed bed of wheat straw, the ozone consumption is described by a set of irreversible, second-order reactions(García-Cubero et al., 2012) and their kinetic expressions such that:

$$
\begin{array}{lcc}
\alpha_{1} O_{3}+\alpha_{2} i L g \rightarrow \alpha_{3} s L g+P_{1} & \text { yields } & R_{1}=k_{1}\left(O_{3, S}\right)(i L g) \\
\alpha_{4} O_{3}+\alpha_{5} s L g \rightarrow P_{2} & \text { yields } & R_{2}=k_{2}\left(O_{3, S}\right)(s L g)
\end{array}
$$

where $\alpha_{I}($ dimensionless $), \alpha_{2}\left(k g \_i L g / k g \_O_{3, S}\right), \alpha_{3}\left(k g \_s L g / k g \_O_{3, S}\right), \alpha_{4}$ (dimensionless), and $\alpha_{5}$ $\left(\mathrm{kg}_{-} S \mathrm{Lg} / \mathrm{kg} \_\mathrm{O}_{3, S}\right)$, are stoichiometric ratios; $k_{1}\left(\left(\mathrm{~kg}_{\text {Straw }} / \mathrm{kg}_{\text {iLig }} / \mathrm{min}\right)\right.$ and $k_{2}\left(\mathrm{~kg}_{\text {Straw }} / \mathrm{kg}_{\text {sLig }} / \mathrm{min}\right)$ are kinetic rate constants; and $P_{1}$ and $P_{2}$ represent products formed during ozonolysis.

The above-derived models (Eqs. 7-10) do not consider residual lignin that remains intact during ozone degradation. Second model was developed based on the cuticle hypothesis that takes into account the residual lignin.

\section{The Cuticle hypothesis}

Lignin does not degrade completely even after a prolonged application of ozone (GarcíaCubero et al., 2009; García-Cubero et al., 2012; Mbachu and Manley, 1981; Neely, 1984). Yokota et al. (2006) reported that delignification during ozonolysis proceeds in a concentric circle from middle lamina towards the secondary wall. In other words, the lignin degradation with ozone first occurs at the outermost layer and extends inward as ozone penetration into the cell wall. To address this phenomenon, it was hypothesized that, as the insoluble lignin in the outermost layer reacts with ozone, the pores in this layer gradually close down forming an impermeable barrier or "cuticle" which prevents ozone from reaching the interior lignin, effectively shutting down mass transfer. This hypothesis is based on previous work conducted on ozonolysis of agricultural residues ( $\mathrm{Li}$ et al., 2015) which demonstrated that smaller particle sizes 
$(50 \mu \mathrm{m})$ had nearly all of the lignin destroyed after ozone pretreatment, whereas larger particles $(400-800 \mu \mathrm{m})$ showed delignification to a much lower degree, despite a lengthy pretreatment time of $1 \mathrm{hr}$. In the model which follows, the particle is considered to consist of two layers: an outer layer which is in contact with the gas phase and can form a cuticle; and an inner layer which is in contact with the cuticle layer. The thickness of the cuticle layer is left as an adjustable parameter to be determined by fitting the model to experimental data.

In the cuticle layer, the above model becomes:

$$
\begin{aligned}
& \varepsilon \frac{\partial O_{3, G}}{\partial t}+u \frac{\partial O_{3, G}}{\partial z}=-K_{O, G C} a_{p}\left(O_{3, G}-\frac{\rho_{S} O_{3, C}}{(1-\varepsilon)}\right) \\
& \frac{\partial O_{3, C}}{\partial t}=\frac{K_{O, G C} a_{p}}{(1-\varepsilon) \lambda_{C}}\left(\frac{(1-\varepsilon)}{\rho_{S}} O_{3, G}-O_{3, C}\right)+\frac{K_{O, C S} a_{p}}{(1-\varepsilon) \lambda_{C}}\left(O_{3, S}-O_{3, C}\right)-\alpha_{1} R_{1, C}-\alpha_{4} R_{2, C} \\
& \frac{\partial\left(s L g_{C}\right)}{\partial t}=\alpha_{3} R_{1, C}-\alpha_{5} R_{2, C} \\
& \frac{\partial\left(i L g_{C}\right)}{\partial t}=-\alpha_{2} R_{1, C}
\end{aligned}
$$

where

$$
\begin{aligned}
& R_{1, C}=k_{1}\left(O_{3, C}\right)\left(i L g_{C}\right) \\
& R_{2, C}=k_{2}\left(O_{3, C}\right)\left(s L g_{C}\right)
\end{aligned}
$$

In the interior solid phase the model equations are:

$$
\begin{aligned}
& \frac{\partial O_{3, S}}{\partial t}=-k_{C S} a_{p} \frac{K_{O, C S} a_{p}}{(1-\varepsilon)\left(1-\lambda_{C}\right)}\left(O_{3, S}-O_{3, C}\right)-\alpha_{1} R_{1, S}-\alpha_{4} R_{2, S} \\
& \frac{\partial\left(s L g_{S}\right)}{\partial t}=\alpha_{3} R_{1, S}-\alpha_{5} R_{2, S} \\
& \frac{\partial\left(i L g_{S}\right)}{\partial t}=-\alpha_{2} R_{1, S}
\end{aligned}
$$


where

$$
\begin{aligned}
& R_{1, S}=k_{1}\left(O_{3, S}\right)\left(i L g_{S}\right) \\
& R_{2, S}=k_{2}\left(O_{3, S}\right)\left(s L g_{S}\right)
\end{aligned}
$$

To account for the reduction in diffusive ozone transport through the cuticle phase as lignin is consumed, the mass transfer coefficient, $K_{O, G C}$, from the gas phase to the cuticle phase and, $K_{O, C S}$, from the cuticle phase to the solid phase, respectively in Eqs.[20a,b] below, are defined so that they decrease in proportion to the amount of insoluble lignin remaining in the cuticle phase:

$$
\begin{aligned}
K_{O, G C} & =\frac{D_{O_{3}}\left(i L g_{C}\right)}{d_{p}\left(\left(i L g_{C, 0}-i L g_{C}\right) \lambda_{C}+i L g_{C}\right)} \\
K_{O, C S} & =\frac{D_{O_{3}}\left(i L g_{C}\right)}{d_{p}\left(i L g_{C, 0}\right) \lambda_{C}} .
\end{aligned}
$$

Note that $\lambda_{c}$ is the fraction of the particle that makes up the cuticle lignin, $D_{O 3}$ is the diffusion coefficient of ozone inside the cuticle and $d_{p}$ is the diameter of the wheat straw particle.

There could be other reasons for the presence of residual lignin after long exposure to ozone, including the formation of a mass transfer barrier as proposed in cuticle hypothesis. The second cause could be the loss of moisture during the ozonolysis of wheat straw. Experimental observation revealed that the moisture content of the wheat straw particles decreased from $48 \%$ by weight initially to about $8 \%$ after 60 min of ozone pretreatment and that ozonolysis was less effective at lower moisture content (Bule et al., 2013; Li et al., 2015; Neely, 1984). Thus at low moisture content ozonolysis process could have been inefficient to degrade the lignin.

A third possibility could be that ozone does not have access to a portion of the lignin in the epidermis cells of the wood. The investigation of the wheat straw cell wall by light microscopy showed that much of the lignin in the epidermis was not degraded during the 
ozonolysis process compared to lignin in the parenchyma cells (Supplementary Fig. 1a-c). The epidermis cells are more compact than the parenchyma cells, and the intercellular spaces (Supplementary Fig. 1d) between epidermal cells are smaller than those in the parenchyma cells. Thus, ozone could have difficulty reaching the lignin layers in the epidermal cells even after prolonged ozonation.

Mathematical models for each of these scenarios could be formulated and fit to the data as in the "cuticle" hypothesis. However, each these models is likely to fit the data equally well and so the model cannot, by itself, tell us which fit is correct: the underlying reason for the residual lignin will have to be determined experimentally.

\section{Results and Discussion}

4.1 Characteristics of biomass materials and model input parameters

The mean diameter of the wheat straw particle was calculated as $0.29 \mathrm{~mm}$ based on the sieve analysis. The initial moisture content of the dried wheat straw was $2 \%$ wet basis (w.b.). A moisture conent of 47\% (w.b.) is recommended (Bule et al., 2012; Neely, 1984) for the efficient interaction of wheat straw with ozone for lignin degradation. Therefore, water was added to the dried wheat straw and soaked overnight to obtain a moisture content of $47 \%$ (w.b.). The bulk density increased and porosity decreased with increasing moisture content: the wheat straw bed porosity and bulk density at 2\% moisture content (w.b) was determined to be 0.88 and 166.1 $\mathrm{kg} / \mathrm{m}^{3}$, respectively, and at a $47 \%$ moisture content (w.b) these values were 0.73 and 191.65

$\mathrm{kg} / \mathrm{m}^{3}$, respectively. The bulk density of the wheat straw in this study was found greater than the previous studies, where it was $62.75 \mathrm{~kg} / \mathrm{m}^{3}$ for a wheat straw particle size of $3.35 \mathrm{~mm}$ (Chevanan et al., 2010). Bulk density increases with decrease in particle size because, with small size of 
particles, pore spaces between paricles decreases leading to increased bulk density (Chevanan et al., 2010). The partice size, bed porosity and bulk density of wheat straw properties were input parameters for the CFD study.

4.2 CFD study

A CFD study was performed to analyze the flow behavior of ozone inside the reactor that enable us to study the ozone and wheat straw interaction for building of simplified model. Pressure drop is one of most important parameters in the design, scale up, operation of packed bed reactors, and prediction of solid-liquid mass transfer. Friction forces due to fluid viscosity at the gas-solid interfaces primarily cause energy dissipation in porous media. An inertial force is caused by successive acceleration and/or deceleration of the fluids across the packing because of local velocity field fluctuations in the gas phase.

Fig. 2(a) is a plot of the measured pressure drop versus the superficial velocity where the triplicate data has been fit to the Ergun equation in Mathematica ${ }^{\circledR}$ using the NonlinearModelFit function. The center line is the fitted curve while the upper and lower lines in this plot represent the mean prediction bands at a $95 \%$ confidence interval. The fitted parameters are the permeability, $\kappa_{b r}=1.26 \times 10^{-11} \pm 2 \% \mathrm{~m}^{2}$, the Forchheimer coefficient, $\beta_{F}=2.48 \times 10^{6} \pm 0 \% \mathrm{~kg} / \mathrm{m}^{4}$, and the sphericity, $\Phi \sim 0.037 \pm 2 \%$. This small sphericity indicates that the particles are not spheroidal and this is consistent with the observation under light microscope that they are somewhat like elongated and flaky compared with the granular particles (Supplementary Fig.1).

These fitted parameters were then incorporated into a COMSOL Multiphysics CFD model of the reactor (Fig. 2b) in order to visualize the flow pattern in a bed of wheat straw particles and to determine if the bed was uniformly contacted with ozone during ozonolysis. Fig. 2(b) shows the streamlines for the ozone flow as well as the ozone distribution inside the reactor 
as a function of time from 0 to $30 \mathrm{sec}$. The well-behaved streamlines imply that ozone was uniformly distributed into the wheat straw bed at $30 \mathrm{sec}$. From this simulation it can be concluded that the ozone was distributed uniformly across the bed within $30 \mathrm{sec}$ of the start of the experiment. The ozone reactions are slow compared with mass transport in the gas phase and solid phases, Eqs. (7 and 11) can be ignored and the ozone concentration in the gas phase can be set to the inlet ozone concentration, simplifying the kinetic models as discussed in section 4.3.

\subsection{Kinetic study and statistical analysis}

The experimentally determined insoluble and soluble lignin content data were fitted to the models using MATLAB R2012a to determine the seven unknown parameter values from the proposed cuticle model described previously (Eqs. 11-20). In addition, the non-cuticle model with six unknown parameters described by Eqs. 7-10 were also fitted to the same experimental data. Initially, it was observed that the optimal parameter values were a function of the initial guesses of those same parameters; in other words the MATLAB program was getting stuck in local minimums. To circumvent this issue, the built-in MATLAB random number generator was used as a means to select the initial guess values for the parameters within a specified range. A range of 0-1 was used for the cuticle parameter $\left(\lambda_{c}\right), 0-2000$ for the kinetic parameters $\left(k_{l}\right.$ and $\left.k_{2}\right), 0-10000$ for the mass-transfer parameter $\left(K_{O, S} a_{p}\right)$, and 0-100 for the stoichiometric parameters $\left(\alpha_{2}, \alpha_{3}\right.$, and $\left.\alpha_{5}\right)$. The stoichiometric parameters $\alpha_{1}$ and $\alpha_{3}$ are dependent parameters whose values were taken as 1 . The program was run through more than 10,000 iterations using sequentially different initial guesses to mathematically determine the minimum of the objective function $(Z)$ with respect to all of these fitted parameters. The objective function was defined as the sum of the squares of the differences between the experimental values $\left(s L g_{E x p}\right.$ and $\left.i L g_{E x p}\right)$ and 
the model predictions for both the soluble ( $s L g_{\text {model }}$ and $\left.s L g_{c, \text { Model }}\right)$ and insoluble lignin ( $i L g_{\text {Model }}$ and $\left.i g_{c, \text { Model }}\right)$. For the case of the cuticle hypothesis the objective function was defined as,

$$
Z=\sum_{i}\left(s L g_{E x p, i}-\left[\left(1-\lambda_{c}\right) s L g_{\text {Model }, i}+\lambda_{c} \cdot s L g_{c, \text { Model }, i}\right]\right)^{2}+\sum_{i}\left(i L g_{E x p, i}-\left[\left(1-\lambda_{c}\right) i L g_{\text {Model }, i}+\lambda_{c} \cdot i L g_{c, \text { Model }, i}\right]\right)^{2}
$$

where $\lambda_{c}$ is the fraction of each particle that is cuticle. For the non-cuticle case the objective function was defined as

$$
Z=\sum_{i}\left(s L g_{E x p, i}-s L g_{\text {Model }, i}\right)^{2}+\sum_{i}\left(i L g_{E x p, i}-i L g_{\text {Model }, i}\right)^{2}
$$

The built-in MATLAB subroutine, lsqnonlin.m, which implements sum of squares minimization and includes parameter constraints, was used with the stiff ordinary differential equation solver, ODE15s, to determine the $Z$ value for each of the 10,000 iterations for both the cuticle model and the non-cuticle model. The lowest $Z$ value obtained through the iterative process signified the global minimum and yielded the best-fit parameter estimates. These best-fit parameter values along with their initial guesses are shown in Table 1, and the resulting fit of the two models to the experimental results are shown in Fig. 3(a-b).

The cuticle model, Fig. 3(a), provides a better fit to the experimental data than the noncuticle model, Fig. 3(b), as quantified by the residual objective function for the two fitted models. In the non-cuticle model, the residual $Z$ value was 0.03513 and for the cuticle hypothesis the $Z$ value was 0.00744099 , more than $20 \mathrm{x}$ improved. This is also apparent in the prediction intervals on the fitted parameters for both models and in the "best-fit" curves generated by the two models. In particular, the cuticle model captures the tendency of the soluble and insoluble lignin concentrations to reach finite values at long times, while in the non-cuticle model, both forms of lignin are predicted to degrade completely over the course of the experiment. 
The cuticle model predicts that $\sim 25 \%$ of the total lignin is in the cuticle phase and that the kinetics are dominated by the destruction of soluble lignin by ozone $\left(k_{2} \sim 1967\right.$ $\left.\mathrm{kg}_{S t r a w} / \mathrm{kg}_{i L_{\mathrm{g}}} / \mathrm{min}\right)$ over the destruction of insoluble lignin by ozone $\left(k_{1} \sim 13.7 \mathrm{~kg}_{S t r a w} / \mathrm{kg}_{s L g} / \mathrm{min}\right)$. In addition, the stoichiometric coefficients show that $\sim 90 \mathrm{~kg} i \mathrm{iLg}_{\mathrm{g}} / \mathrm{kg}_{\mathrm{Oz}}$ of insoluble lignin is required to produce $\sim 18 \mathrm{~kg} s L g / \mathrm{kg}_{O z}$ of soluble lignin by ozonolysis. Then, $\sim 0.08 \mathrm{~kg}_{s L g} / \mathrm{kg}_{O z}$ of soluble lignin can be destroyed per kg of ozone treatment and the base mass transfer rate $\left(K_{O, S} a_{p}\right)$ for the ozone to diffuse through the different lignin phases is $\sim 12 \mathrm{~min}^{-1}$. The estimated parameter values were determined meaningful $(<100 \%$ error $)$ by a statistical analysis.

A statistical analysis was performed on the proposed models to determine the $95 \%$ confidence intervals $\left(C I_{i}\right)$ for each best-fit parameter $\left(\theta_{i}\right)$ and the $95 \%$ prediction interval $(P I)$ for a new observation based on the development in Ryan (Ryan, 2009). Briefly,

$$
\begin{aligned}
& C I_{i}=\theta_{i} \pm t_{\alpha / 2, D O F} \cdot \sigma \sqrt{c_{i i}} \\
& P I_{i}=y_{\text {model }, i} \pm t_{\alpha / 2, D O F} \cdot \sigma \sqrt{1+\mathbf{J}_{\theta_{0}} \cdot c \cdot \mathbf{J}_{\theta_{0}}^{T}}
\end{aligned}
$$

where $t_{\alpha / 2, D O F}$ is the student's $t$ inverse cumulative distribution function for a $100(1-\alpha) \%$ confidence interval where $\alpha=0.05$ for a $95 \%$ confidence interval, $D O F$ is the degrees of freedom (number of data points - number of parameters $=59$ for cuticle and 60 for non cuticle cases, respectively), $\sigma$ is the standard error defined as $\sqrt{Z / D o F}, c_{i i}$ is the $\mathrm{i}^{\text {th }}$ diagonal element of the covariance matrix, and $\mathbf{J}$ is the Jacobian matrix. The covariance matrix and the Jacobian vector are obtained from the following equations,

$$
\mathbf{c}=\left(\mathbf{J}_{\theta_{0}} \mathbf{J}_{\theta_{0}}^{T}\right)^{-1}
$$




$$
\mathbf{J}_{\theta_{0}}=\left.\frac{\partial f\left(t_{i}, \theta\right)}{\partial \theta}\right|_{\theta-\theta_{0}}
$$

where the Jacobian matrix was numerically approximated using the following formula (Butt, 2008),

$$
\mathbf{J}_{\theta_{0}} \approx \frac{f\left(t_{i}, \theta_{0}+\delta\right)-f\left(t_{i}, \theta_{0}-\delta\right)}{2 \delta}
$$

where $\delta$ is some small number, typically the square root of the machine precision (Beers, 2007).

Different $\delta$ values provided different confidence intervals on the parameters due to singularities that arise in the calculation of the covariance matrix for specific set of equations used in this study. For instance, too large a $\delta$ value often resulted in a singular matrix most likely due to numerical noise on optimization surfaces. As a result, small values of $\delta$ value gave unrealistically small confidence intervals $(<1 \%)$ for the parameters. The authors decided to use a $\delta$ value that gave the most numerically stable covariance matrix and this was accomplished by minimizing the condition number $(\kappa)$. The condition number, is defined as

$$
\kappa=\frac{\lambda_{\text {max }}}{\lambda_{\text {min }}}
$$

where $\lambda_{\max }$ is the largest eigenvalue of the covariance matrix and $\lambda_{\min }$ is the smallest eigenvalue of the covariance matrix, is a measure of the numerical stability of the covariance matrix (Won et al., 2013), where a lower value signifies a well-conditioned matrix. The eigenvalues of any square matrix can be directly computed in MATLAB. The $\delta$ values that yielded the smallest condition number were $10^{-13}$ and $10^{-12}$ for the cuticle and non-cuticle case, respectively (Fig. $4 \mathrm{a}$ and b). The $95 \%$ confidence intervals, their percent difference from the best-fit estimates, and the lowest objective function from the 10,000 iterations for both models are tabulated in Table 1 . 
The 95\% confidence intervals on the fitted parameters are much larger for the non-cuticle model than for the cuticle model. In addition, in the non-cuticle model all of the parameters except $k_{2}$ have more than $100 \%$ error. Also, the $95 \%$ prediction intervals, shown as the upper and lower dashed curves from the fitted model in Fig. 3(a) and Fig. 3(b) further support the cuticle hypothesis since they are narrower for the cuticle model than for the non-cuticle model. The prediction intervals are still quite broad for the cuticle model, which the authors attribute to scatter in the experimental data.

The overall lignin reduction in wheat straw biomass at different ozone pretreatment times can be satisfactorily predicted from the derived reaction kinetics, mass transfer coefficients, physical characteristics of wheat straw and the reactor configuration. However, this model does not take into account the effects of lignin concentration on sugar yield. Therefore, the relationship between the insoluble lignin content with the glucose and xylose yield and were experimentally derived as discussed in section 4.4 .

4.4 Relationship between the glucose yield and xylose yield with insoluble lignin content

In order to show the scope of the simulated results for the prediction of the sugar yield, experiments were conducted to study the effects of the change of insoluble lignin in the xylose yield and the glucose yield. The ozonated wheat straw was enzymatically hydrolyzed and the percentage of hydrolyzed glucose and xylose was correlated with acid insoluble lignin. A linear relationship was found between the glucose yield and the insoluble lignin and xylose yield and insoluble lignin (Fig. 5). The predicted insoluble lignin derived from the above model could be useful to estimate the glucose yield and xylose yield using the following correlation:

Glucose Yield $=73.23-2.51(i \mathrm{Lg})$

Xylose Yield $=39.942-1.71(i \mathrm{Lg})$ 
The glucose and xylose yield increased with decreased insoluble lignin content, however, recovery was slower below $9 \%$ of acid insoluble lignin (Fig.5). This could be due to the inhibitors of enzymatic hydrolysis produced during the ozonolysis process (Panneerselvam et al., 2013). Enzymatic hydrolysis yield improved from $18 \%$ (untreated) to $60 \%$ for pretreated wheat straw. The results are in accordance with the results obtained by the previous study (GarcíaCubero et al., 2009; Li et al., 2015).

The ozone lignin interaction model with the cuticle hypothesis could be used to predict the ozone lignin interaction process. In other words, the developed kinetic model can estimate the change in insoluble lignin at different pretreatment time. Then, by using the relationship between the glucose yield and the insoluble lignin, the tentative amount of sugar yield can be estimated.

\section{Conclusions}

This study proposed two mathematical models for ozonolysis of wheat straw: one based on the work of Garcia-Cubero et al. (2012) and another including an outer "cuticle" region. The CFD study revealed that the ozone distribution in the reactor would be uniform and steady in the bed within $30 \mathrm{sec}$ of the start of reactor. Confidence interval and condition number showed that the cuticle based model provided a better fit to the experimental results. The kinetic parameters derived in this study can be utilized for the design and scale up of ozone reactor for the pretreatment of wheat straw.

\section{Acknowledgements}

This material is based upon work supported by the National Science Foundation under Research Grant No. (1231085).

\section{Appendix A. Supplementary data}




\section{References}

1. ASABE. 2007. ASABE Standards. 2007. S269.4. Cubes, pellets and crumbles Definitions and methods for determining density, durability and moisture content.

2. Ballesteros, I., Negro, M., Oliva, J., Cabañas, A., Manzanares, P., Ballesteros, M. 2006. Ethanol Production From Steam-Explosion Pretreated Wheat Straw. in: Twenty-Seventh Symposium on Biotechnology for Fuels and Chemicals, (Eds.) J. McMillan, W. Adney, J. Mielenz, K.T. Klasson, Humana Press, pp. 496-508.

3. Beers, K.J. 2007. Numerical methods for chemical engineering : applications in Matlab®. Cambridge University Press, Cambridge, UK ; New York.

4. Binder, A., Pelloni, L., Fiechter, A. 1980. Delignification of straw with ozone to enhance biodegradability. Eur. J. Appl. Microbial. 11, 1-5.

5. Bule, M.V., Gao, A.H., Hiscox, B., Chen, S. 2013. Structural Modification of Lignin and Characterization of Pretreated Wheat Straw by Ozonation. J. Agr. Food Chem. 61, 39163925.

6. Butt, R. 2008. Introduction to numerical analysis using MATLAB. Jones \& Bartlett Learning., Hingham, Mass.

7. Carman, P.C. 1956. Flow of gases through porous media. Butterworths Scientific Publications London.

8. CEN/TC. 2004. 335 Solid Biofuels Methods for determination of moisture content. Oven dry method. Part 1 Total moisture Reference method,

9. Chevanan, N., Womac, A.R., Bitra, V.S., Igathinathane, C., Yang, Y.T., Miu, P.I., Sokhansanj, S. 2010. Bulk density and compaction behavior of knife mill chopped switchgrass, wheat straw, and corn stover. Bioresour. Technol. 101, 207-214.

10. Dean, R.C. 1953. Aerodynamic Measurements. MIT, Gas Turbine Laboratory Cambridge, Mass

11. García-Cubero, M.T., González-Benito, G., Indacoechea, I., Coca, M., Bolado, S. 2009. Effect of ozonolysis pretreatment on enzymatic digestibility of wheat and rye straw. Bioresour. Technol. 100, 1608-1613.

12. García-Cubero, M.T., Palacín, L.G., González-Benito, G., Bolado, S., Lucas, S., Coca, M. 2012. An analysis of lignin removal in a fixed bed reactor by reaction of cereal straws with ozone. Bioresour. Technol. 107, 229-234.

13. Lam, P., Sokhansanj, S., Bi, X., Lim, C., Naimi, L., Hoque, M., Mani, S., Womac, A., Narayan, S., Ye, X. 2008. Bulk density of wet and dry wheat straw and switchgrass particles. Appl. Eng. Agric. 24, 351-358.

14. Lapierre, C., Pollet, B., Rolando, C. 1995. New insights into the molecular architecture of hardwood lignins by chemical degradative methods. Res. Chem. Intermediat 21, 397-412.

15. Li, C., Wang, L., Chen, Z., Li, Y., Wang, R., Cai, G., Li, Y., Yu, Q., Lu, J. 2015. Ozonolysis Pretreatment of Maize Stover: the Interactive Effect of Sample Particle Size and Moisture on Ozonolysis Process. Bioresour. Technol. 183, 240-247.

16. Mandavgane, S.A., Yenkie, M. 2011. Effect of $\mathrm{pH}$ of the medium on degradation of Aqueous ozone. Rasayan J. Chem. 4, 544-547

17. Mbachu, R.A.D., Manley, R.S.J. 1981. Degradation of lignin by ozone. I. The kinetics of lignin degradation of ozone. J. Polymer. Sci. Polymer. Chem. Ed. 19, 2053-2063.

18. Neely, W.C. 1984. Factors affecting the pretreatment of biomass with gaseous ozone. Biotechnol. Bioeng. 26, 59-65. 
19. Panneerselvam, A., Sharma-Shivappa, R.R., Kolar, P., Ranney, T., Peretti, S. 2013. Potential of ozonolysis as a pretreatment for energy grasses. Bioresour. Technol. 148, 242-248.

20. Pedersen, M., Meyer, A.S. 2009. Influence of substrate particle size and wet oxidation on physical surface structures and enzymatic hydrolysis of wheat straw. Biotechnol. Progr. 25, 399-408.

21. Petersen, M.Ø., Larsen, J., Thomsen, M.H. 2009. Optimization of hydrothermal pretreatment of wheat straw for production of bioethanol at low water consumption without addition of chemicals. Biomass Bioenerg. 33, 834-840.

22. Rakness, K., Gordon, G., Langlais, B., Masschelein, W., Matsumoto, N., Richard, Y., Robson, C.M., Somiya, I. 1996. Guideline for measurement of ozone concentration in the process gas from an ozone generator.

23. Ryan, T.P. 2009. Modern regression methods. 2nd ed. Wiley, Hoboken, N.J.

24. Saha, B.C., Iten, L.B., Cotta, M.A., Wu, Y.V. 2005. Dilute acid pretreatment, enzymatic saccharification and fermentation of wheat straw to ethanol. Process Biochem. 40, 36933700.

25. Sluiter, A., Hames, B., Ruiz, R., Scarlata, C., Sluiter, J., Templeton, D., Crocker, D. 2006. Determination of structural carbohydrates and lignin in biomass. Laboratory Analytic Procedures LAP-002.

26. Sun, Y., Cheng, J. 2002. Hydrolysis of lignocellulosic materials for ethanol production: a review. Bioresour. Technol. 83, 1-11.

27. Talebnia, F., Karakashev, D., Angelidaki, I. 2010. Production of bioethanol from wheat straw: an overview on pretreatment, hydrolysis and fermentation. Bioresour. Technol. 101, 4744-4753.

28. Thompson, R., Isaacs, G. 1967. Porosity determination of grains and seeds with air comparison pycnometer. Transactions of the ASAE 10, 693-696.

29. Travaini, R., Otero, M.D.M., Coca, M., Da-Silva, R., Bolado, S. 2013. Sugarcane bagasse ozonolysis pretreatment: effect on enzymatic digestibility and inhibitory compound formation. Bioresour. Technol. 133, 332-339.

30. USDA. 2014. World Agricultural Supply and Demand Estimates (WASDE-532)

31. Whitaker, S. 1996. The Forchheimer equation: a theoretical development. Transport Porous Med. 25, 27-61.

32. Won, J.H., Lim, J., Kim, S.J., Rajaratnam, B. 2013. Condition-number-regularized covariance estimation. J. Roy. Statist. Soc. Ser. B 75, 427-450.

33. Wu, J., Upreti, S., Ein-Mozaffari, F. 2013. Ozone pretreatment of wheat straw for enhanced biohydrogen production. Int. J. Hydrogen Energy 38, 10270-10276.

34. Yokota, S., Iizuka, K., Ishiguri, F., Abe, Z., Yoshizawa, N. 2006. Ozone-dioxane delignification from the cell walls of Japanese cypress (Chamaecyparis obtusa Endl.). J. Mater. Cycles Waste 8, 140-144. 
Table 1. Unknown parameters for the cuticle model and non-cuticle model with the initial guesses, the resulting best fit parameter estimates, the $95 \%$ confidence intervals, and the $\%$ difference from the best-fit estimates. Also included are the final values of the objective function for each model.

\begin{tabular}{|c|c|c|c|c|}
\hline Parameter (units) & Initial Guess* & $\begin{array}{l}\text { Best-Fit } \\
\text { Estimate }\end{array}$ & $\begin{array}{l}\text { 95\% Confidence } \\
\text { Interval }(+/-)\end{array}$ & $\%$ \\
\hline \multicolumn{5}{|l|}{ Cuticle Model } \\
\hline$k_{1}\left(\mathrm{~kg}_{\text {Straw }} / \mathrm{kg}_{\text {iLig }} / \mathrm{min}\right)$ & 6.777454980061437 & 13.7835 & 0.6965 & 5.05 \\
\hline$k_{2}\left(k_{\text {Straw }} / k g_{\text {sLig }} / \min \right)$ & 971.11233465248324 & 1967.0163 & 32.5080 & 1.65 \\
\hline$K_{O, C S}\left(\mathrm{~min}^{-1}\right)$ & 7314.4748134208558 & 11.5053 & 0.3972 & 3.45 \\
\hline$\lambda_{c}($ dimensionless $)$ & 0.53697145322376971 & 0.2539 & 0.0123 & 4.85 \\
\hline$\alpha_{2}\left(k g_{i L i g} / k_{O z}\right)$ & 49.325636412865187 & 90.0579 & 2.6275 & 2.92 \\
\hline$\alpha_{3}\left(\mathrm{~kg}_{\mathrm{sLig}} / \mathrm{kg}_{\mathrm{Oz}}\right)$ & 10.031039386097987 & 17.7611 & 0.6175 & 3.48 \\
\hline$\alpha_{5}\left(k_{g_{s L i g}} / \mathrm{kg}_{O z}\right)$ & 0.99448195065703349 & 0.0873 & 0.0050 & 5.77 \\
\hline$Z\left(k g_{\text {Lig }} / k_{\text {Straw }}\right)$ & \multicolumn{4}{|c|}{0.00744099} \\
\hline \multicolumn{5}{|l|}{ Non- Cuticle Model } \\
\hline$k_{1}\left(k_{\text {Straw }} / k g_{\text {iLig }} / \mathrm{min}\right)$ & 1550.1472953868779 & 25.5557 & 59.1084 & 231.29 \\
\hline$k_{2}\left(k_{\text {Straw }} / \mathrm{kg}_{\text {sLig }} / \mathrm{min}\right)$ & 1625.9254836138264 & 1999.4693 & 1339.1831 & 66.98 \\
\hline$K_{O, S} a_{p}\left(\min ^{-1}\right)$ & 7775.6515448158061 & 11.6691 & 39.8399 & 341.41 \\
\hline$\alpha_{2}\left(k_{i L i g} / k_{g z}\right)$ & 23.101405596685005 & 49.9978 & 284.5448 & 569.11 \\
\hline$\alpha_{3}\left(\mathrm{~kg}_{\mathrm{sLig}} / \mathrm{kg}_{\mathrm{Oz}}\right)$ & 11.722055630824871 & 9.5837 & 60.5809 & 632.12 \\
\hline$\alpha_{5}\left(k_{g_{s L i g}} / k_{g_{O z}}\right)$ & 14.5723911125671 & 0.0466 & 0.2847 & 610.78 \\
\hline$Z\left(k g_{\text {Lig }} / k g_{\text {Straw }}\right)$ & \multicolumn{4}{|c|}{0.03513126} \\
\hline
\end{tabular}

*All digits are necessary to reproduce final results. 
a

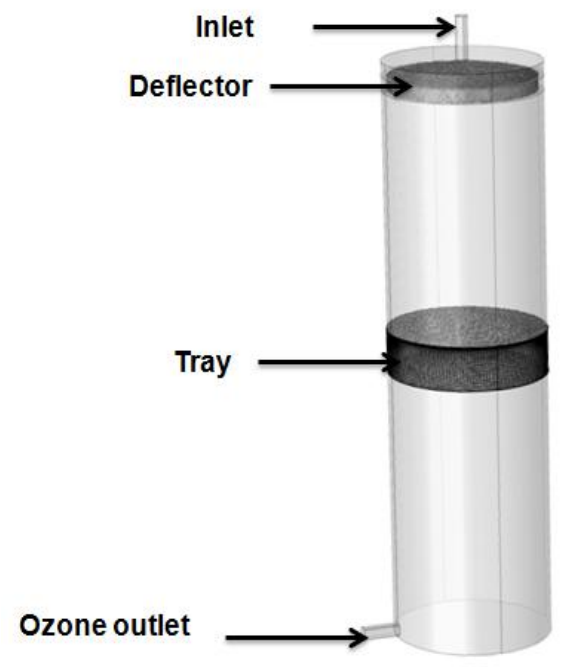

b

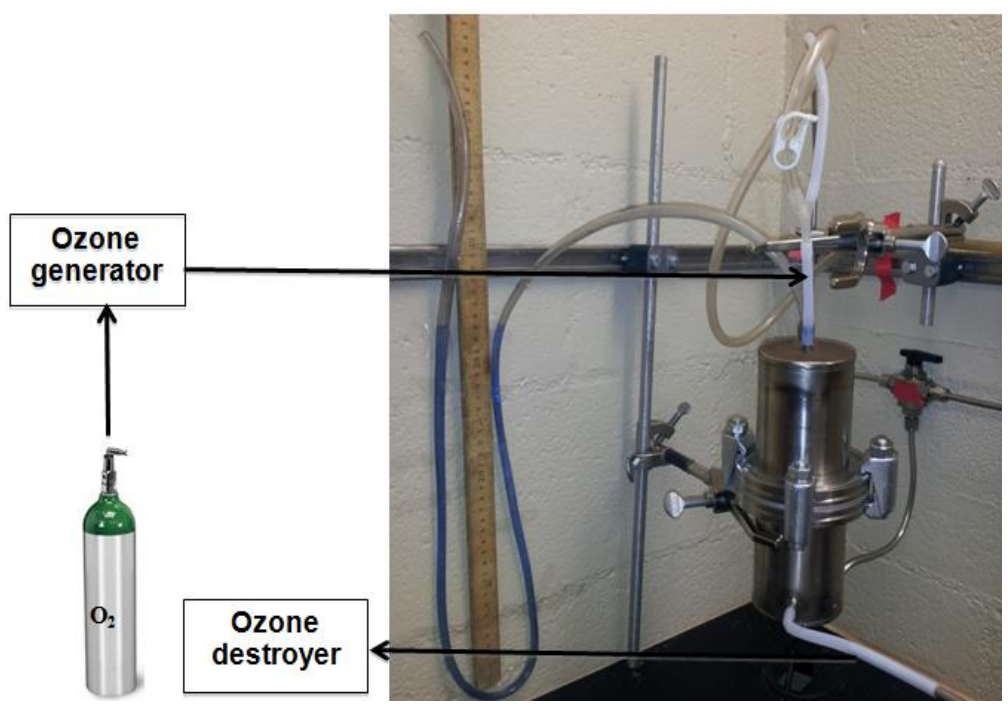

Fig. 1. (a) Ozone reactor configuration; (b) schematic of the experimental apparatus 
a

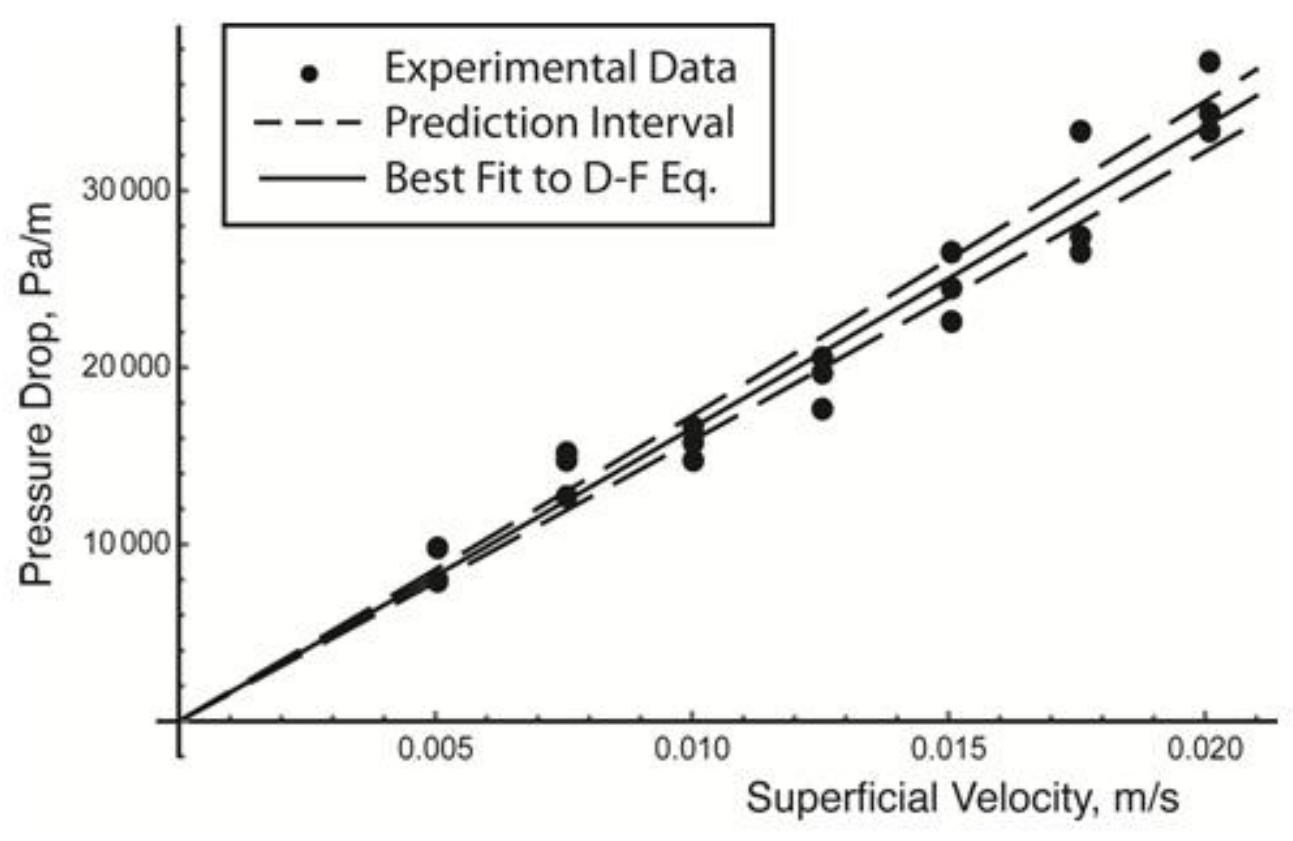

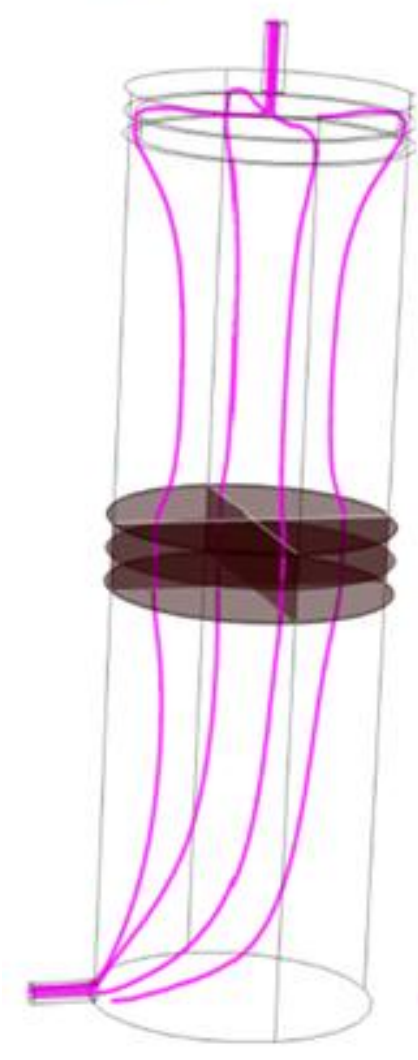

$t=0$ sec

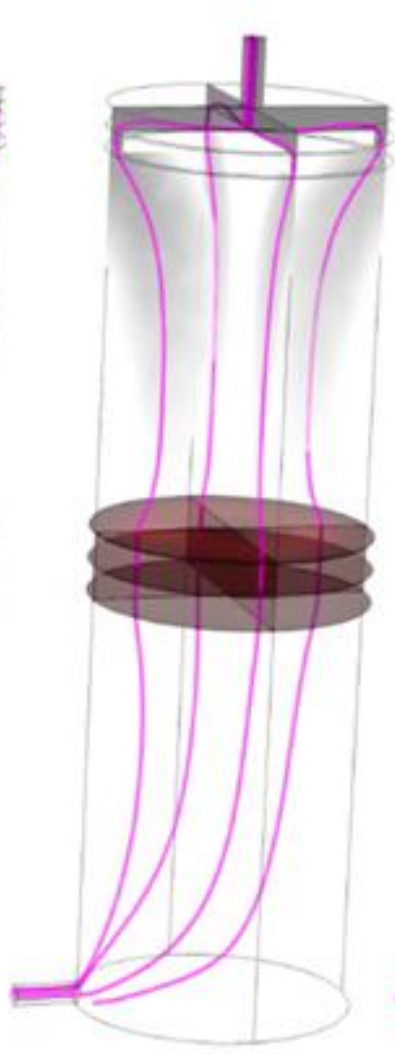

$\mathrm{t}=10 \mathrm{sec}$

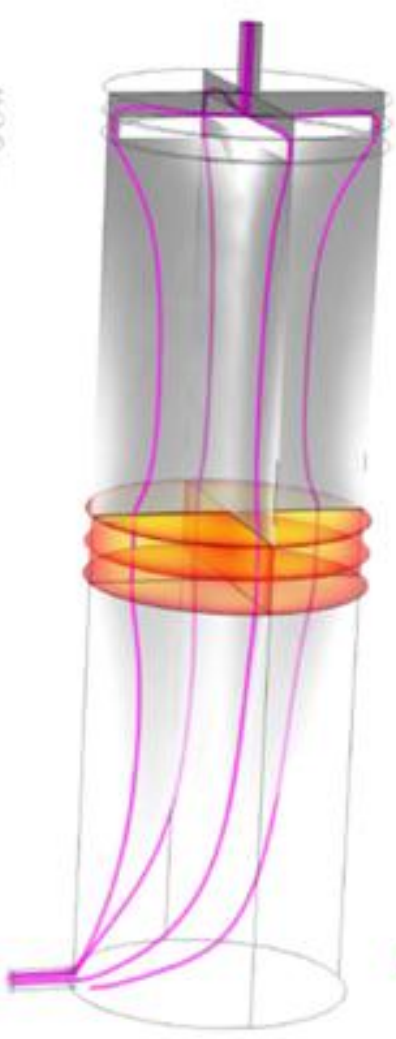

$t=20 \mathrm{sec}$

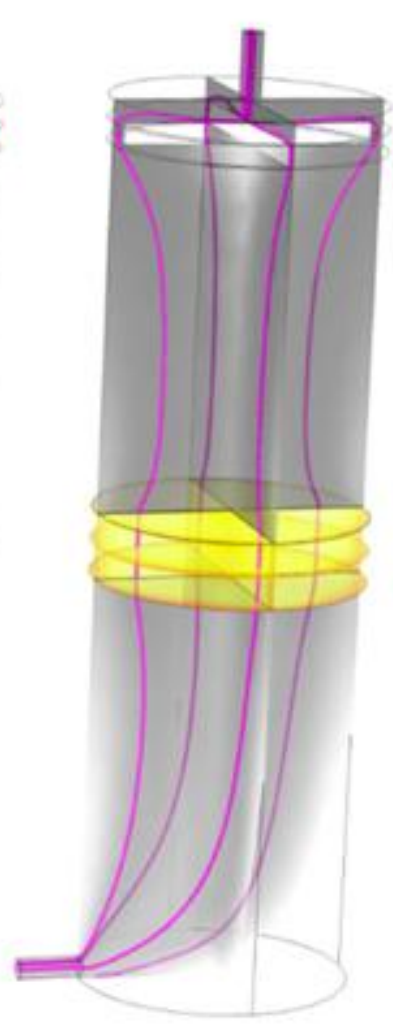

$t=30 \mathrm{sec}$

Fig. 2. (a) Changes in measured(dotted) and predicted (solid line) pressure drop with superficial velocity; (b) velocity distribution inside the ozone reactor derived from the COMSOL CFD model. The smooth steamlined indicates the direction of flow from top to bottom throughout the reactor. The grey shading represents $\mathrm{O}_{3}$ in the gas phase and the yellow (white in black and white printing) shading is $\mathrm{O}_{3}$ in the particulate straw phase. Note that the $\mathrm{O}_{3}$ concentration in the bed is distributed uniformly in about $30 \mathrm{~s}$. 

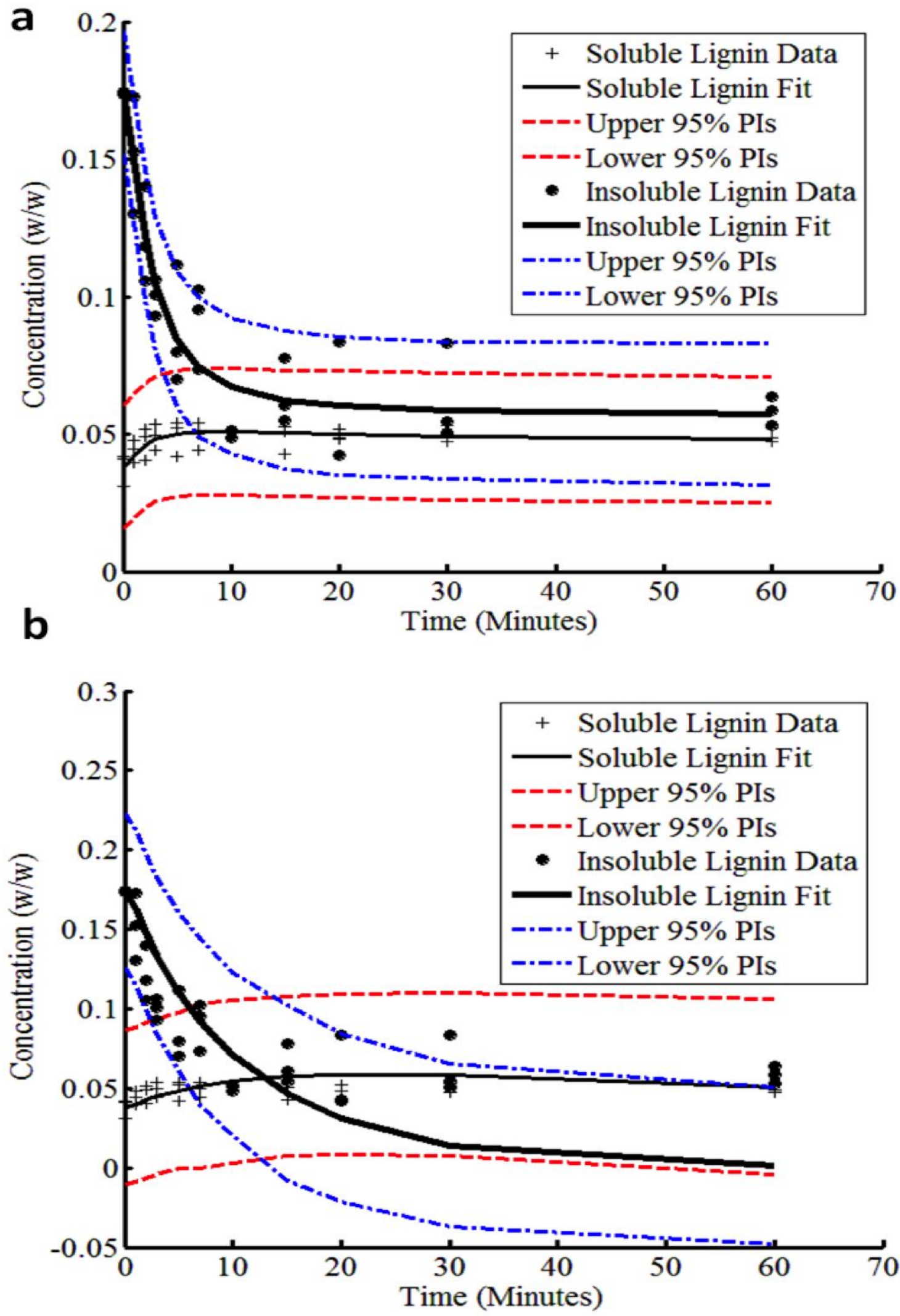

Fig. 3. Measured and predicted soluble lignin and insoluble lignin concentration with confidence intervals a) by the use of cuticle hypothesis and b) without employing cuticle hypothesis. 

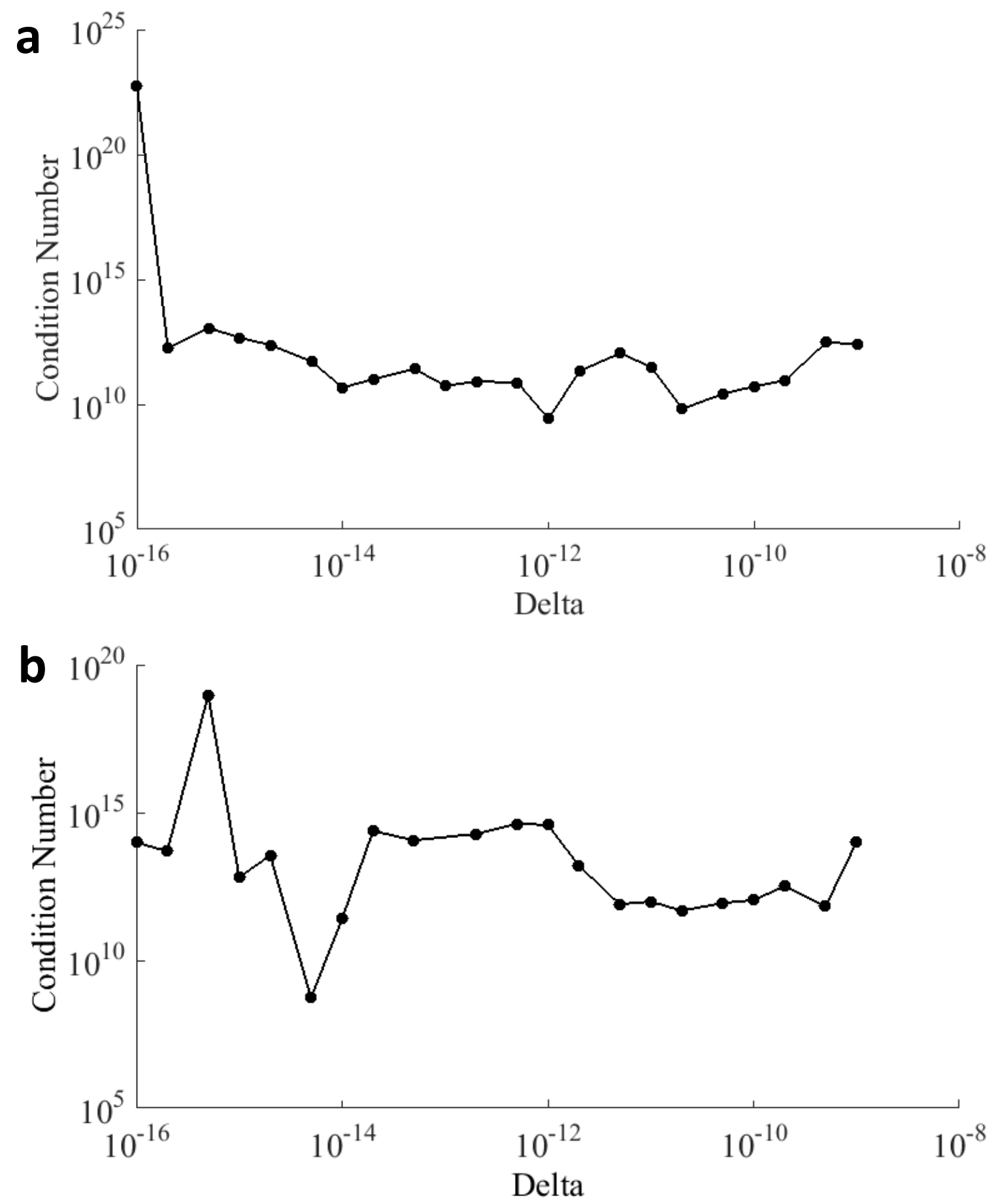

Fig. 4. (a) Condition number for the cuticle model as a function of delta and (b) condition number for the noncuticle model as a function of delta. 


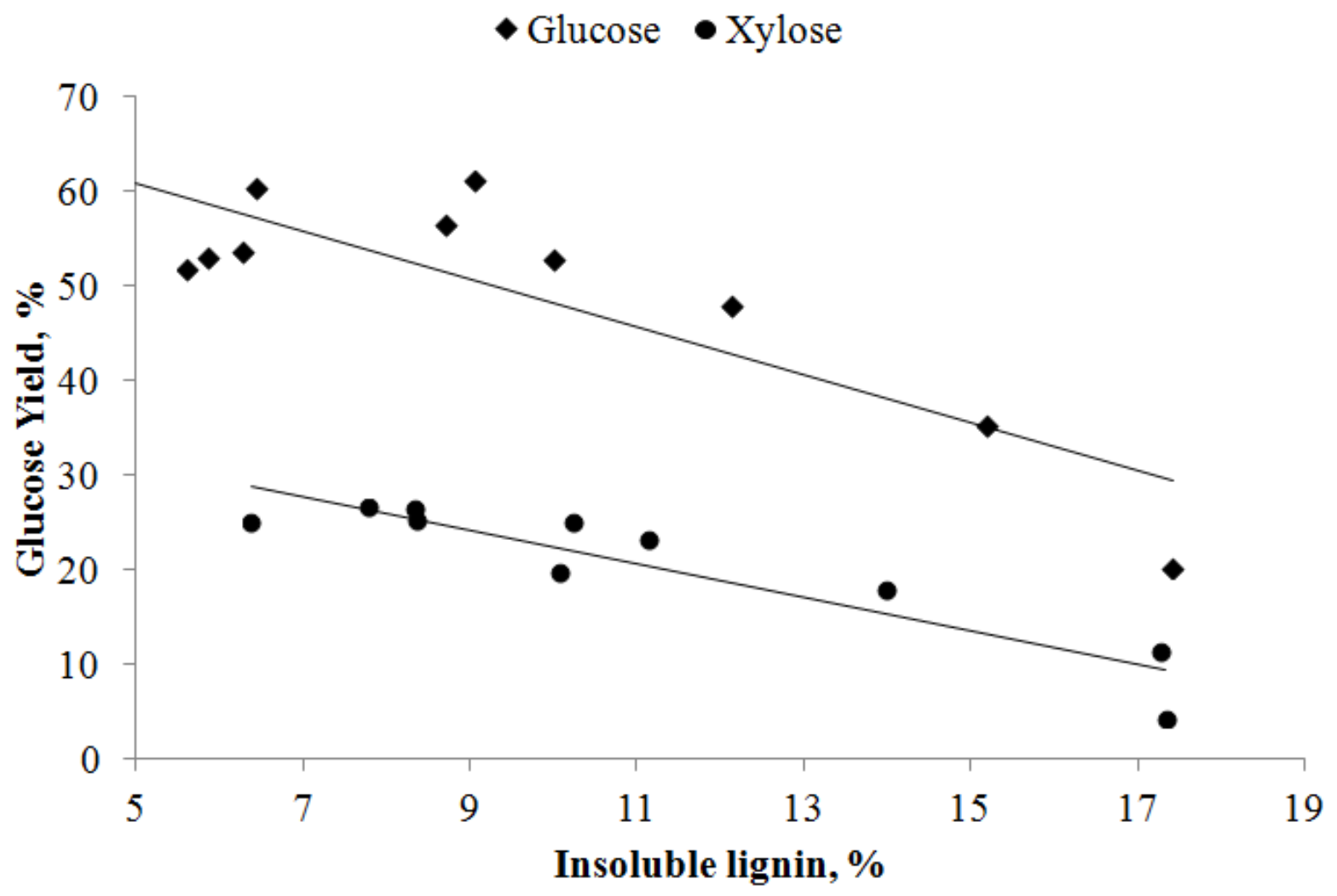

Fig. 5. Relationship between glucose yield and xylose yield with insoluble lignin content derived from experiments (data sets were the average of two replications). 